\title{
The use of imbricated sutures in radioactive plaque brachytherapy surgery
}

This article was published in the following Dove Press journal:

Clinical Ophthalmology

12 March 2010

Number of times this article has been viewed

\author{
Kaan Gündüz' \\ Jose S Pulido' \\ Peter D Yeakel ${ }^{2}$ \\ Michael King ${ }^{3}$ \\ Kelly L Classic' \\ Keith M Furutani² \\ 'Department of Ophthalmology, \\ ${ }^{2}$ Department of Radiation Oncology, \\ ${ }^{3}$ Section of Media Support Services, \\ Mayo Clinic, Rochester, MN, USA
}

\begin{abstract}
This paper describes a new technique to suture the radioactive plaque to sclera. The radioactive plaque is conventionally sutured to the sclera using 5/0 nylon sutures. The imbricated suture technique involves using a $1 / 0$ silk or $2 / 0$ mersilene suture imbricated with the $5 / 0$ nylon suture when the nylon suture is tied and cut. The imbricated suture technique allows easy identification of the plaque at removal and provides a surface that separates the $5 / 0$ nylon from the surface of the eyelet platform, making suture cutting easier and safer. The radiation exposure times ranged from 9.1 minutes to 14 minutes (mean: 10.8 minutes) during plaque insertion and from 2.8 to 3.3 minutes (mean: 3.0 minutes) during plaque removal with the imbricated suture technique. This technique may decrease radiation exposure time and may prevent inadvertent scleral damage.

Keywords: plaque radiotherapy, Iodine-125, Ruthenium-106, Collaborative Ocular Melanoma Study, choroidal melanoma, ciliary body melanoma, retinoblastoma, plaque placement, plaque removal, radiation exposure
\end{abstract}

\section{Introduction}

Plaque radiotherapy is one of the most commonly used methods in the treatment of choroidal and ciliary body melanoma. ${ }^{1,2}$ Plaque radiotherapy has also been used in the treatment of retinoblastoma ${ }^{3}$ and choroidal hemangioma. ${ }^{4}$ One of the difficulties encountered in plaque radiotherapy pertains to removal of the plaque. After the plaque has stayed on the eye for an average period of 3-7 days depending on the radioisotope being used and the radioactivity of the plaque, there may be radiation-induced changes in the conjunctiva and Tenon's capsule. ${ }^{5}$ These tissues usually become edematous and there may even be a marked inflammatory reaction around the plaque. The identification of the plaque and anchoring sutures at the time of plaque removal may become a serious problem, especially when the plaque is placed posterior to the equator. In this paper, we propose an alternative method of plaque placement whereby imbricated sutures are used to facilitate in the removal of the plaque.

\section{Methods}

Plaque placement procedures are usually done under general anesthesia. After conjunctival peritomy, dissection of the tenon's fascia, and isolation of the rectus muscles, the dummy plaque is brought into the field. Usually three or four eyelets on the plaque are marked on the sclera. After the dummy plaque is removed, 5/0 nylon sutures are placed through the eyelet marks on the sclera. The radioactive plaque is then brought in position on the globe and 5/0 nylon sutures are passed through the previously noted eyelets on the plaque. At this point, $1 / 0$ silk suture or $2 / 0$ mersilene is imbricated with the $5 / 0$ nylon suture 
Plaque radiotherapy is a commonly used treatment method for choroidal and ciliary body melanoma. One of the difficulties encountered with plaque radiotherapy pertains to removal of the plaque.

After the plaque has stayed on the eye for approximately 3-7 days, there may be radiation induced changes in the conjunctiva and Tenon's capsule. These tissues can become edematous and there may be inflammation around the plaque. Identification of the plaque and anchoring sutures at the time of plaque removal may become a serious problem.

The images below illustrate an alternative method of plaque placement whereby imbricated sutures are used to facilitate the removal of the plaque.

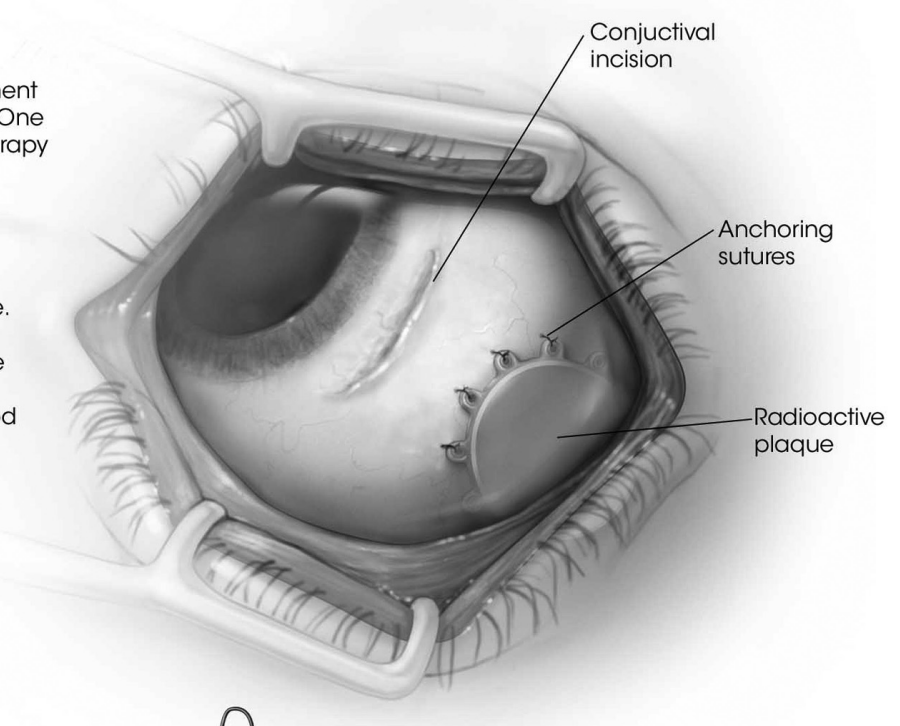

A.

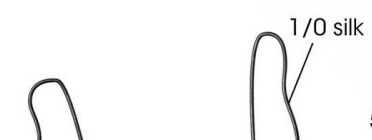

A 1.0 silk suture is imbricated with a $5 / 0$ nylon suture at the time of plaque placement

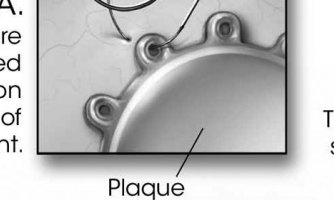

B.

The 5.0 nylon uture is tied and cut.

Plaque

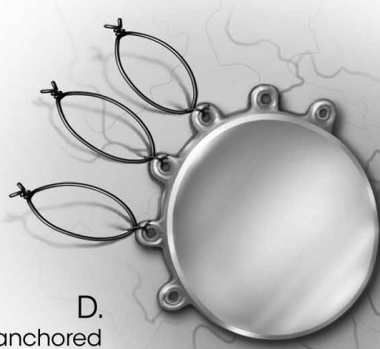

The plaque is anchored to the scleral surface with

3- 4 imbricated sutures.

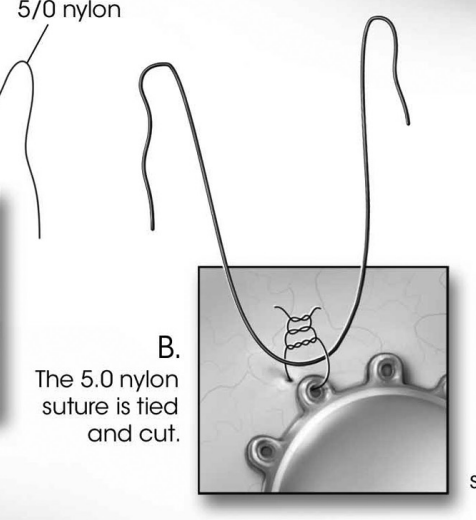

silk suture is tied and cut approximately $1 \mathrm{~cm}$ above the scleral surface.

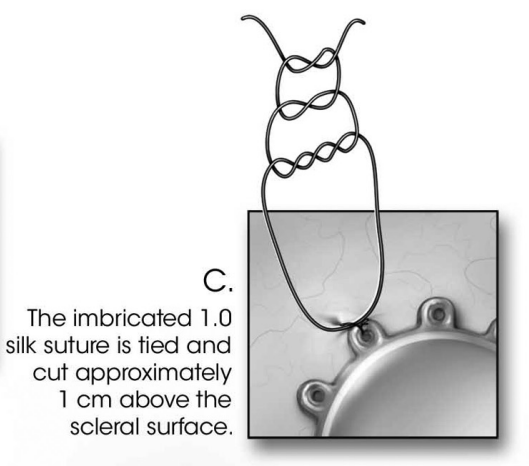

E.

At the time of removal the imbricated sutures
are easily found under the conjunctiva and followed back to the plaque eyelet.

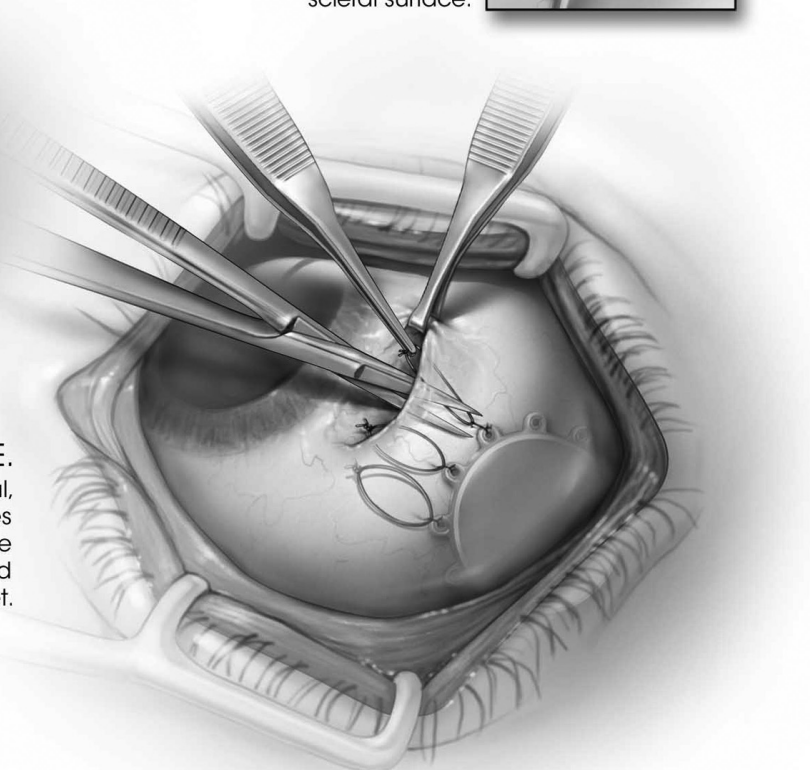

Figure I.A) The I/0 silk suture is imbricated with the $5 / 0$ nylon suture at the time of plaque placement. B) After the $1 / 0$ silk suture has been imbricated, the $5 / 0$ nylon is tied and cut. C) The imbricated I/0 silk suture is tied about I cm above the scleral surface D) The imbricated I/O silk suture is then cut. E) Plaque removal:After the conjunctiva is opened the imbricated sutures are easily found under the conjunctiva and followed back to the plaque. 
(Figure 1A) when the nylon suture is tied and cut (Figure 1B). The $1 / 0$ silk or $2 / 0$ mersilene is also tied about $1 \mathrm{~cm}$ above the sclera (Figure 1C) and cut (Figure 1D). The conjunctiva is brought anteriorly over the plaque and imbricated silk sutures and closed with 7/0 interrupted vicryl sutures.

Plaque removal procedures are usually done under monitored care local anesthesia. At the time of plaque removal, the conjunctival sutures are cut and removed. The imbricated silk or mersilene sutures are easily found under the conjunctiva and followed back to the plaque (Figure 1E). The imbricated silk/mersilene suture and the nylon suture are then cut together at the level of the plaque eyelet and removed. The plaque is subsequently removed. The sclera is inspected for any remaining silk suture fragments. The conjunctiva is closed with interrupted sutures.

Iodine-125 COMS (Collaborative Ocular Melanoma Study) plaques were used in this study but the technique can easily be modified for all plaque types as well. Radiation exposure times during plaque insertion and removal were measured. During plaque insertion, the time spent for suturing the plaque on the sclera using imbricated sutures was recorded. Recording of the time was started with the bringing of the plaque on the sclera and stopped at the completion of the last suture securing the plaque to the sclera. Similarly, the time spent for removal of the plaque was recorded. Time recording was started with the visualization of the plaque after opening the conjunctiva. Time recording was stopped with removal of the plaque from the sclera out of the surgical field. All surgical procedures were done in the presence of the senior author, JSP, in the operation room.

\section{Results}

This technique was used in approximately 140 plaque radiotherapy procedures performed over the past four years. Plaque insertion times ranged from 9.1 minutes to 14 minutes (mean: 10.8 minutes) and plaque removal times ranged from 2.8 to 3.3 minutes (mean: 3.0 minutes). We did not encounter any surgical complications related to suture removal. None of the patients reported significant pain during the relatively short plaque removal procedure.

\section{Discussion}

The widely used surgical technique for plaque placement involves using 5/0 nylon suture to secure the plaque to the sclera. The suture ends are cut long, about $1 \mathrm{~cm}$ above the scleral surface. This may allow easier detection of the sutures at the time of plaque removal. However, it does not address the problem of cutting the suture that is firmly attached to the plaque and sclera. The imbricated suture technique besides allowing localization of the radioactive plaque readily also provides a surface that separates the 5/0 nylon from the surface of the eyelet platform, making suture cutting easier and safer at plaque removal. This is an advantage especially for posteriorly located plaques. Every new technique takes a bit of learning curve time but in the end this technique is not much longer at initial plaque placement but markedly diminishes removal time. The radiation exposure times recorded in our study showed that the surgeon was subject to less than 10.8 minutes of radiation exposure time during plaque insertion which shows that the addition of the extra sutures does not add time to the placement while the removal exposure times were only about three minutes. Though there is little in the literature about plaque placement and removal times, these removal exposure times appear quite low.

\section{Disclosures}

The authors report no conflicts of interest in this work.

\section{References}

1. The Collaborative Ocular Melanoma Study Group: The COMS randomized trial of I-125 brachytherapy for choroidal melanoma, III. Initial mortality findings. COMS report no. 18. Arch Ophthalmol. 2001;119:969-982.

2. Gündüz K, Shields CL, Shields JA, et al. Plaque radiotherapy of uveal melanoma with predominant ciliary body involvement. Arch Ophthalmol. 1999;177:592-597.

3. Shields CL, Mashayekhi A, Sun H, et al. Iodine 125 plaque radiotherapy as salvage treatment for retinoblastoma recurrence after chemoreduction in 84 tumors. Ophthalmology. 2006;113:2087-2092.

4. Madreperla SA, Hungerford JL, Plowman PN, Laganowski HC, Gregory PT. Choroidal hemangiomas: visual and anatomic results of treatment by photocoagulation or radiation therapy. Ophthalmology. 1997;104:1773-1778; discussion, 1779.

5. Damato BE. Ocular Tumors: Diagnosis and treatment. Oxford, UK: Butterworth Heinemann; 2000:209-222.
Clinical Ophthalmology

\section{Publish your work in this journal}

Clinical Ophthalmology is an international, peer-reviewed journal covering all subspecialties within ophthalmology. Key topics include: Optometry; Visual science; Pharmacology and drug therapy in eye diseases; Basic Sciences; Primary and Secondary eye care; Patient Safety and Quality of Care Improvements. This journal is indexed on Submit your manuscript here: http://www.dovepress.com/clinical-ophthalmology-journal

\section{Dovepress}

PubMed Central and CAS, and is the official journal of The Society of Clinical Ophthalmology (SCO). The manuscript management system is completely online and includes a very quick and fair peer-review system, which is all easy to use. Visit http://www.dovepress.com/ testimonials.php to read real quotes from published authors. 